\title{
Effect of Sodium-Glucose Cotransporter Type 2 Inhibitors on Clinical Outcomes in Patients With Cardiovascular Disease: A Meta-Analysis of Randomized Controlled Trials
}

\section{Caiyun Zheng}

Fujian Medical University Affiliated Fuqing City Hospital

Meimei Lin

Fujian Medical University Affiliated Fuqing City Hospital

\section{Yan Chen}

Fujian Medical University Affiliated Fuqing City Hospital

Haiting Xu

Fujian Medical University Affiliated Fuqing City Hospital

\section{Lingqun Yan}

Fujian Medical University Affiliated Fuqing City Hospital

Hengfen Dai ( $\nabla$ hengfendai2011@163.com)

Fujian Medical University Affiliated Fuzhou First Hospital: Fuzhou First Hospital

https://orcid.org/0000-0002-2037-4208

\section{Original investigation}

Keywords: sodium glucose cotransporter type 2 inhibitors, cardiovascular disease, mortality, metaanalysis

Posted Date: January 29th, 2021

DOI: https://doi.org/10.21203/rs.3.rs-154500/v1

License: (c) (i) This work is licensed under a Creative Commons Attribution 4.0 International License. Read Full License

Version of Record: A version of this preprint was published at Cardiovascular Diabetology on April 22nd, 2021. See the published version at https://doi.org/10.1186/s12933-021-01272-z. 


\section{Abstract}

\section{Background}

Controlled studies and observational studies have shown that sodium-glucose cotransporter type 2 inhibitors (SGLT-2s) are beneficial to the mortality of patients with heart failure (HF). However, it is unclear whether SGLT-2s can benefit patients with other cardiovascular diseases. Here, we conducted a systematic review and meta-analysis to determine the clinical benefits of SGLT-2s in cardiovascular patients with or without diabetes.

Methods

We searched PubMed, EMBASE, Cochrane Library, Web of Science databases, and ClinicalTrials.gov databases for randomised controlled trials written in English from inception until November 1, 2020. Two reviewers independently identified randomised controlled trials comparing the effects of SGLT-2s in patients with cardiovascular disease with or without diabetes. Primary outcomes were all-cause mortality, cardiovascular mortality, and hospitalisation for heart failure. Secondary outcomes were major adverse events from cardiovascular, metabolic, renal, and infectious diseases. The effects of SGLT-2s were evaluated using RevMan5.3 software. The Cochrane risk of bias tool was used to assess study quality.

Results

We identified 10 randomised controlled trials (24500 patients in the SGLT-2 group and 17960 patients in the placebo group). Meta-analysis showed that SGLT-2 treatment significantly reduced all-cause mortality, cardiovascular mortality, and hospitalisation for heart failure (HHF) in patients with cardiovascular disease (all-cause mortality relative risk [RR]: $0.86 ; 95 \%$ confidence interval [Cl]: $0.80-0.91 ; P<0.00001 ; P^{2}$ $=11 \%$; cardiovascular mortality RR: $0.85 ; 95 \%$ Cl: 0.79-0.92; $P<0.0001 ; P^{2}=35 \%$; HHF RR: $0.69 ; 95 \%$ Cl: $\left.0.64-0.81 ; P<0.00001 ; P^{2}=0 \%\right)$. In patients with heart failure, mortality and HHF after SGLT-2 treatment for heart failure with reduced ejection fraction were significantly reduced, whereas heart failure with preserved ejection fraction did not differ compared with placebo treatment. Moreover, SGLT-2s induced a lower incidence of renal damage and myocardial infarction than the placebo group; however, the risk of infection, amputation, volume depletion, and diabetic ketoacidosis was higher.

\section{Conclusions}

In this exploratory analysis, SGLT-2s had significant clinical effects in the treatment of patients with cardiovascular disease and had significant benefits in terms of renal function and myocardial infarction, but were associated with increased risk of infection, ketoacidosis, amputation, and volume depletion.

\section{Background}

The prevalence of cardiovascular disease is increasing, and cardiovascular disease has remained the leading cause of morbidity and mortality worldwide for the last 20 years. Cardiovascular diseases include 
myocardial infarction, stroke, atherosclerotic cardiovascular diseases, hypertension, atrial fibrillation, and heart failure. Among them, myocardial infarction and stroke are the main causes of complications and death in patients with diabetes mellitus[1]. Among patients with cardiovascular disease, those with type 2 diabetes (T2DM) comprise a higher-risk subgroup, and T2DM has been shown to be an independent risk factor. Long-lasting diabetes is often complicated by atherosclerosis, heart failure, and chronic kidney disease. Therefore, for patients with heart failure or chronic kidney disease combined with diabetes, mortality and hospitalisation for heart failure (HHF) are greatly increased. Many recent clinical studies have shown that sodium-glucose cotransporter type 2 inhibitors (SGLT-2s) show very good clinical effects in patients with T2DM and cardiovascular diseases [2,3]. Diabetes mellitus is not the only cause of cardiovascular disease, and cardiovascular disease from other causes is associated with a higher risk of poor prognosis. Therefore, any drug needs to be evaluated for efficacy and safety in a wide range of patients with cardiovascular diseases, regardless of the presence of T2DM as a comorbidity.

SGLT-2s are a new class of medicines for the treatment of T2DM. Inhibiting the expression of SGLT-2 protein in the renal tubules of the kidneys, which reduces the reabsorption of glucose in the kidneys, increases the excretion of glucose in the urine and reduces the level of glucose in the blood plasma[4, 5]. Currently, eight SGLT-2s (canagliflozin, dapagliflozin, empagliflozin, ertugliflozin, luseogliflozin, ipragliflozin, sotagliflozin, and tofogliflozin) have been approved worldwide for the treatment of T2DM, either as monotherapy or in combination with other hypoglycaemic drugs. In addition, SGLT-2s have been shown to reduce cardiovascular risk events, including lowering blood pressure, improving weight loss, lowering haemoglobin A1c levels, reducing myocardial infarction, reducing stroke, and reducing cardiovascular death in people with T2DM $[6,7]$. In the last 5 years, large randomised controlled trials in patients with T2DM have shown that SGLT-2s improve cardiovascular and renal outcomes, particularly outcomes of patients with heart failure [8, 9]. AstraZeneca's dapagliflozin has been approved in the European Union for the treatment of adult patients with symptomatic heart failure with reduced ejection fraction (HFrEF), regardless of whether the patients had T2DM [10]. However, it is still unclear whether the clinical benefits of SGLT-2s can be extended to all patients with cardiovascular diseases.

Therefore, in this study, we conducted a meta-analysis of the clinical outcomes of SGLT-2s in patients with cardiovascular diseases, with or without T2DM, and explored the relationships among clinical efficacy, the heart failure subtype, and the SGLT-2 type.

\section{Materials And Methods}

\section{Data sources and search strategy}

Eligible studies were identified by searching PubMed, EMBASE, Cochrane Library, Web of Science, and ClinicalTrials.gov databases. Searches were conducted by two study investigators independently by the end of November 1, 2020. Search keywords included "cardiovascular disease +", "CVD", "cardiovascular death", "cardiovascular mortality", "coronary artery disease", "CAD", "heart failure", "HF", "myocardial infarction", "stroke", "+", "atrial fibrillation", "SGLT-2", and "sodium-glucose co-transporter 2 inhibitors". The 
search strategies are detailed in Multimedia Appendix 1. The search was restricted to human studies. References for the identified studies were also retrieved to identify studies that may be eligible. Only articles written in English were considered. There were no restrictions on the publication date.

\section{Inclusion and exclusion criteria}

Eligible patients included patients with cardiovascular disease, with or without T2DM. Patients with other age-related comorbidities were not excluded. Patients in the intervention group were treated with SGLT-2s (canagliflozin, dapagliflozin, empagliflozin, ertugliflozin, luseogliflozin, ipragliflozin, sotagliflozin, and tofogliflozin) for a period of time. Patients who received a placebo or drugs other than SGLT-2s were used as controls. The primary outcomes were all-cause mortality, cardiovascular death, and HHF. The secondary outcomes were adverse cardiovascular reactions, adverse reactions in endocrine, renal side adverse reactions, infection, and other adverse reactions.

\section{Data extraction and quality assessment}

The included studies reported all-cause mortality, cardiovascular mortality, and HHF. All literature titles and abstracts were initially screened for relevance to exclude studies that were not meaningful to our research by two reviewers. Drs. Zheng and Dai independently analysed the full text and extracted data from selected studies; divergence was settled by discussion and consensus or by third-party arbitration. The risk assessment tool for Cochrane bias was used, and the included randomised controlled trials (RCTs) were assessed according to the literature assessment criteria in the Cochrane Systematic Review Manual[11].

\section{Data synthesis and analysis}

Meta-analyses were conducted using Cochrane's Review Manager (RevMan) version 5.3 (The Cochrane Collaboration, Copenhagen, Denmark) and R programming language, version 3.6.3 (R Foundation for Statistical Computing, Guangzhou, China). We used the associated relative risk (RR) with $95 \%$ confidence intervals (Cls) to evaluate clinical outcomes (efficacy and safety) in patients with cardiovascular disease receiving standard treatment with or without SGLT-2s. We assessed whether the results of the included studies were consistent. Chi-square tests were used to assess heterogeneity, and $R^{2}$ was used for quantitative analysis. Values of $P \geq 0.05$ and $R^{2} \leq 50 \%$ were not considered to represent heterogeneity, and fixed-effect models were used. In contrast, $P<0.05$ and $P>50 \%$ indicated significant heterogeneity among the different studies. Sensitivity analysis was performed by successively deleting each study and reanalysing the dataset for all remaining studies. Publication bias was assessed using funnel plots and Egger's tests. $P$ values less than 0.05 (two-tailed) were considered statistically significant, and we did not adjust for multiple testing.

\section{Results}

\section{Search results}


In total, 7351 articles were retrieved from PubMed, EMBASED, Cochrane Library, and Web of Science databases, and 108 articles were retrieved from ClinicalTrials.gov. After removing duplicate studies, the remaining 5763 articles were screened. After reading 33 eligible full-text articles, 23 were excluded, and 10 studies (total of 42682 participants) met our inclusion criteria[12-21]. The systematic search results are presented in Fig. 1. HF patient data from cardiovascular outcome trials were available from published post-hoc studies[22, 23].

\section{Basic characteristics and quality evaluation of the literature}

In total, 42682 patients were included in 10 RCTs (25108 patients in the intervention group and 18574 patients in the control group). The detailed baseline characteristics of each study are presented in Table S1. Quality evaluation was conducted using the Cochrane systematic evaluation method, and the included studies had a low risk of overall bias, as shown in Figure S1.

\section{Primary outcomes}

The summarised outcomes of our meta-analysis are presented in Table S2. To evaluate the primary outcomes, 10 trials were included in the meta-analysis. Estimates of primary outcomes for all-cause mortality, cardiovascular mortality, and hospitalisation for heart failure are shown in Figs. 2-4.

All-cause mortality

All 10 articles contained all-cause mortality outcomes, with a total of 43682 patients ( 25108 in the SGLT-2 group and 18574 in the placebo group; RR: $0.86 ; 95 \% \mathrm{Cl}: 0.80-0.91 ; P<0.00001 ; P=0 \%$; Fig. 2 ).

Cardiovascular mortality

Nine articles contained outcomes of cardiovascular death (24933 in the SGLT-2 group and 18421 in the placebo group). Subgroup analysis showed that cardiovascular death was significantly lower in patients using SGLT-2s than in the placebo group (RR: $0.85 ; 95 \% \mathrm{Cl}: 0.79-0.92 ; P<0.0001 ; P^{2}=26 \%$; Fig. 3 ).

\section{HHF}

Nine articles included outcomes for HHF (24959 in the SGLT-2 group and 18436 in the placebo group). Meta-analysis showed that HHF was significantly lower in patients using SGLT-2 than in the placebo group (RR: $0.69 ; 95 \%$ Cl: $0.64-0.74 ; P<0.00001 ; P^{2}=0 \%$; Fig. 4)

\section{Secondary outcomes}

Adverse cardiovascular outcomes

There were five studies with adverse cardiovascular events, including four with myocardial infarction. The five studies included 28983 patients (17753 in the SGLT-2 group and 11230 in the placebo group). Metaanalysis results showed that the incidence of myocardial infarction was significantly lower in patients 
receiving SGLT-2 inhibitors than in those receiving a placebo (RR: $0.90 ; 95 \% \mathrm{Cl}: 0.82-0.99 ; P=0.03 ; P^{2}=$ $32 \%$ ). Five studies with stroke outcomes included 29248 patients (17869 in the SGLT-2 group and 11379 in the placebo group). Meta-analysis results indicated that there were no significant differences in the incidence of stroke between patients treated with SGLT-2 inhibitors and those treated with a placebo (RR: $0.98 ; 95 \%$ Cl: $0.86-1.11 ; P=0.72 ; P^{2}=21 \%$; Fig. 5).

Adverse endocrine outcomes

In total, 30719 patients (18645 in the SGLT-2 group and 12074 in the placebo group) were included in the six studies on hypoglycaemia outcomes. Meta-analysis results showed that there were no significant differences in the incidence of hypoglycaemia between patients using SGLT-2s and those using the placebo (RR: $1.00 ; 95 \%$ Cl: $0.96-1.05 ; P=0.87 ; P^{2}=8 \%$ ).

Additionally, 34796 patients (20674 in the SGLT-2 group and 14122 in the placebo group) were included in six studies of outcomes related to diabetic ketoacidosis. Meta-analysis results showed that the incidence of diabetic ketoacidosis in patients treated with SGLT-2s was significantly higher than that in patients treated with a placebo (RR: $3.65 ; 95 \% \mathrm{Cl}$ : $1.83-7.27 ; P=0.0002 ; I^{2}=0 \%$; Fig. 6).

Adverse renal outcomes

In the four trials, there were no significant differences in compound outcomes of acute renal failure between the SGLT-2 and placebo groups (RR: $1.00 ; 95 \% \mathrm{Cl}: 0.90-1.11 ; P=0.99 ; P^{2}=84 \%$ ). Sensitivity analysis was performed by sequentially deleting each study and reanalysing the datasets for all remaining studies (RR: $0.99,95 \% \mathrm{Cl}: 0.90-1.10, P=0.96 ; P^{2}=80.8 \%$; Table S3). In total, 35124 patients with acute renal injury were included in seven articles (20850 in the SGLT-2 group and 14274 in the placebo group). Meta-analysis results showed that the incidence of acute renal injury in patients treated with SGLT-2s was significantly lower than that in patients treated with a placebo (RR: $0.80 ; 95 \%$ Cl: $0.68-$ $0.93 ; P=0.004 ; P^{2}=0 \%$; Fig. 7).

Adverse infection outcomes

Outcomes of infection, including urinary tract infection, male genital infection, and female genital infection, were evaluated. The results suggested that the incidence of infection in patients treated with SGLT-2s was significantly higher than that in patients treated with a placebo $(P<0.05)$. The results of urinary tract infection were assessed in four articles, which included a total of 25720 patients (16146 in the SGLT-2 group and 9574 in the placebo group). Meta-analysis results showed that the incidence of urinary tract infection in patients treated with SGLT-2 inhibitors was significantly higher than that in patients treated with a placebo (RR: $1.08 ; 95 \% \mathrm{Cl}: 1.01-1.15 ; P=0.02 ; P=39 \%$ ).

Results of male and female genital infections were included in the three articles, which involved a total of 25400 patients ( 15975 in the SGLT-2 group and 9425 in the placebo group). Meta-analysis results showed that the incidence of male and female genital infections in patients treated with SGLT-2s was 
significantly higher than that in patients treated with a placebo (male: RR: $3.35 ; 95 \%$ Cl: $2.90-3.87 ; P<$ $0.00001 ; P^{2}=0 \%$; female: RR: $3.85 ; 95 \%$ Cl: $3.43-4.32 ; P<0.00001 ; P^{2}=0 \%$; Fig. 8 ).

Others

Five articles containing fracture outcomes included 34533 patients (20543 in the SGLT-2 group and 13990 in the placebo group). Meta-analysis results showed that there were no significant differences in fracture incidence between patients treated with SGLT-2s and those treated with a placebo (RR: 1.11; 95\% Cl: $0.99-1.23 ; P=0.08 ; P^{2}=24 \%$ ).

Four articles included outcomes of amputation involving 27513 patients ( 15856 in the SGLT-2 group and 11657 in the placebo group). Meta-analysis results showed that the incidence of amputation in patients treated with SGLT-2s was significantly higher than that in patients treated with a placebo (RR: $1.42 ; 95 \%$ Cl: $\left.1.18-1.71 ; P=0.0002 ; P^{2}=32 \%\right)$.

Six articles included outcomes of volume depletion in 30719 patients (18645 in the SGLT-2 group and 12074 in the placebo group). Meta-analysis results showed that the volume depletion of patients treated with a placebo was significantly lower than that of patients treated with SGLT-2s (RR: $1.22 ; 95 \%$ Cl: $1.11-$ 1.33; $P<0.0001 ; P^{2}=45 \%$; Fig. 9).

\section{Subgroup analysis}

Detailed forest plots displaying subgroup analyses are presented in the Supporting Information. For all outcomes in the overall cardiovascular disease population, no subgroup effect was observed upon stratification by T2DM status (Figs. S2-S4). In a subgroup analysis of heart failure types, there were no significant differences in all-cause mortality, cardiovascular mortality, or HHF between the SGLT-2 and placebo groups among patients with heart failure with preserved ejection fraction (HFpEF; Figs. S5-S7). SGLT-2s reduced all-cause mortality, cardiovascular mortality, and HHF largely independent of drug type, with the exception of ertugliflozin and sotagliflozin (Figs. S8-S10). In terms of safety, only the subgroup analysis of ketoacidosis and acute renal injury was performed because of the limited number of included trials. In terms of ketoacidosis, canagliflozin and ertugliflozin showed significant differences compared with the placebo group, whereas the other drugs showed no significant differences. There were no significant differences in acute renal failure between patients administered dapagliflozin, canagliflozin, or ertugliflozin and patients administered a placebo (Fig. S11). Empagliflozin significantly reduced the number of acute renal failure events (Fig. S12).

\section{Sensitivity analysis results}

Sensitivity analysis was performed to compare all-cause mortality by sequentially removing one study at a time and observing the exaggerated effect this had on the overall results. As shown in Fig. 10, after each study was excluded, the pooled RR of the remaining included studies was approximately 0.87 , with 
no significant change, suggesting that the results of this meta-analysis were stable and reliable. Removing any study did not affect the overall results (Fig. 10).

\section{Publication bias}

Using funnel plots drawn by Review Manager 5.3, we visually assessed the publication bias of all-cause mortality (Egger's test $P=0.3638,95 \% \mathrm{Cl}-0.662-0.669$ ). All evidence suggested that the probability of publication bias was low. Funnel plots were not generated for other comparisons because fewer than 10 studies were included (Fig. 11).

\section{Discussion}

To the best of our knowledge, this is the first study comparing SGLT-2s with a placebo in comprehensive outcomes of primary efficacy and adverse events in cardiovascular diseases in patients with and without T2DM. Cardiovascular diseases include various conditions, such as common coronary artery disease, hypertension, dyslipidaemia, congenital heart disease, valvular disease, and arrhythmia. Accordingly, cardiovascular diseases are a serious threat to human health worldwide. Cardiovascular outcomes, survival, and prognosis in patients with cardiovascular diseases are relatively poor. In a previous metaanalysis, SGLT-2 treatment of patients with T2DM significantly reduced all-cause mortality, cardiovascular mortality, HHF, risk of HF, and renal failure [24-28]. Moreover, among participants with established cardiovascular disease, regardless of the presence or absence of T2DM, SGLT-2s significantly reduce mortality and major adverse cardiovascular events (MACEs) compared with the placebo, and the benefit for the prevention and treatment of HF and renal disease is consistent with that of earlier metaanalyses[29]. The same results were observed in the HFrEF population; however, there were no significant differences in patients with HFpEF and no significant differences between the two groups for most adverse events. The results for the risk of infection, amputation, and hypovolemia should be interpreted with caution.

SGLT-2s were superior to the placebo or other glucose-lowering drugs in terms of the pooled primary efficacy outcomes, including all-cause mortality, cardiovascular mortality, HHF, and renal benefits from EMPA-REG OUTCOME[12, 30], CANVAS-R[13, 31], CANVAS [32, 33], CREDENCE[34, 35], DECLARE-TIMI $58[36,37]$, and VERTIS-CV trials [20,38]. In the EMPA-REG OUTCOME trial, all eligible patients had established cardiovascular disease, and empagliflozin reduced the risk of all-cause mortality by $32 \%$, cardiovascular mortality by $38 \%$, and HHF by $35 \%$ compared with the placebo. At the same time, the study confirmed that the dose of empagliflozin did not affect the hazard ratios of cardiovascular outcomes. In the CANVAS and CANVAS-R trials, treatment resulted in reductions of $49 \%$ for all-cause mortality, $47 \%$ for cardiovascular mortality, $30 \%$ for HHF, and $22 \%$ for major adverse cardiovascular events. Patients in the canagliflozin group had a lower risk of cardiovascular mortality, HHF, and renal failure than those in the placebo group at a median follow-up of 2.62 years in the CREDENCE trial. In the DECLARE-TIMI 58 trial, dapagliflozin appeared to robustly reduce the risk of cardiovascular mortality or HHF and MACEs in patients with T2DM and previous myocardial infarction. In the VERTIS-CV trial 
involving patients with T2DM and established atherosclerotic cardiovascular disease, ertugliflozin was shown to be noninferior to the placebo with MACEs. However, the incidence of cardiovascular mortality or HHF did not differ significantly between the two groups. Owing to the diverse properties of different drugs, we cannot exclude the possibility that differences among the agents in this class may result in real differences in clinical outcomes. It is also possible that the effects of individuals are similar because the confidence interval of VERTIS CV overlaps with that of previous trials. Owing to limited literature on the HFpEF population, the role of SGLT-2s in patients with HFpEF remains unclear. In current research on HFpEF, only the subgroup analyses in the DECLARE-TIMI 58 and VERTIS-CV trials suggested a potential impact on HHF or cardiovascular mortality. Two ongoing clinical trials in patients with HFpEF will provide further evidence of its efficacy (NCT03057951 and NCT01297257).

In terms of safety, three available studies showed neutral effects on myocardial infarction and stroke in patients receiving SGLT-2s [39-41]. In an RCT and a nationwide cohort study, the results showed no increased risk of hypoglycaemia with SGLT-2 monotherapy [42, 43]; however, SGLT-2s were associated with approximately twice the risk of diabetic ketoacidosis as DPP4 inhibitors [44]. Accordingly, clinicians should be cautious when combining SGLT-2s with other hypoglycaemic drugs. SGLT-2s reduced the risk of dialysis, transplantation, or death due to kidney disease in individuals with T2DM, with or without basic renal disease, and provided protection against acute kidney injury[45-47]. The use of SGLT-2s was not associated with an increased risk of fracture and amputation compared with other antidiabetics [44, 48-50]. Volume depletion is another major concern, not consistent with recent studies, which showed significant differences between SGLT-2s and other oral hypoglycaemic agents in volume depletion events[51-53], perhaps because of individualised dosing of SGLT-2s. Other potential side effects include urinary tract infection and male/female genital infection, which may be attributed to the selective inhibition of renal proximal tubule glucose reabsorption by SGLT-2s. According to the United States Food and Drug Administration, all manufacturers are required to add a warning of potential infection to the prescribing information and patient medication guide for all SGLT-2s in 2018. Although these adverse events should not mask the overall cardio-renal benefits of SGLT-2s [54-56], individuals at risk of these complications should be monitored closely, and treatment should be reconsidered or discontinued if such complications occur.

Our study had some limitations. First, confounding factors, such as age, sex, regionalism, baseline haemoglobin A1c, estimated glomerular filtration rate, and exposure to cardiovascular disease-related drugs, as well as drug combinations and other potential factors, were difficult to control. Second, articles published in languages other than English were excluded. Third, few RCTs of certain SGLT-2 drugs in the HFpEF population have been published. Finally, this meta-analysis may be underpowered for comparison of long-term adverse events between SGLT-2s and the placebo owing to the different durations of follow up for the included RCTs. Therefore, additional studies are required to confirm our findings.

\section{Conclusion}


This meta-analysis showed that initiation of SGLT-2s was associated with substantially lower allcause/cardiovascular mortality and lower HHF in patients with cardiovascular disease and in both diabetic and nondiabetic patients. However, no benefit was observed in patients with HFpEF. SGLT-2s increased the risk of amputation, infection, volume depletion, and diabetic ketoacidosis, but slowed the decline in renal function and myocardial infarction adverse outcomes compared with a placebo. These findings have important implications for the future direction of SGLT-2 therapy in cardiovascular disease research, but more studies are needed to determine the mechanism of SGLT-2s in cardiovascular disease treatment, as well as large RCTs to demonstrate the clinical efficacy of SGLT-2s in a specific cardiovascular disease.

\section{Abbreviations}

T2DM: type 2 diabetes; HHF: hospitalisation for heart failure; SGLT-2: sodium-glucose cotransporter type 2 inhibitor; HFrEF: heart failure with reduced ejection fraction; HFpEF: heart failure with preserved ejection fraction; RCT: randomised controlled trial; RR: relative risk; MACE: major adverse cardiovascular event.

\section{Declarations}

\section{Acknowledgements}

None.

\section{Authors' contributions}

CYZ conceived the meta-analysis. CYZ and HFD developed the research strategy and provided statistical expertise. HFD drafted the manuscript. All Authors contributed to the development of the selection criteria, risk of bias assessment strategy, and data extraction criteria. All Authors read, provided feedback, and approved the final manuscript.

\section{Funding}

This work was supported by the Startup Fund for Scientific Research of Fujian Medical University (2017XQ1206) and Fuzhou Science and Technology Project Funds (2018-S-105-2). The funders of the study had no role in the study design, data collection, data analysis, data interpretation, or writing of the report.

\section{Availability of data and materials}

Not applicable.

\section{Ethics approval and consent to participate}

Not applicable. 


\section{Consent for publication}

Not applicable.

\section{Competing interests}

The authors declare that they have no competing interests.

\section{Authors' details}

${ }^{1}$ Affiliated Fuqing City Hospital of Fujian Medical University, No. 267 Qingrong Avenue, Fuqing, Fuzhou 350300, Fujian, China. ${ }^{2}$ Fujian Medical University, No. 1 Xueyuan Road, University Town, Fuzhou 350122, Fujian, China. ${ }^{3}$ Affiliated Fuzhou First Hospital of Fujian Medical University, No. 190, Dadao Road, Taijiang District, Fuzhou 350009, Fujian, China.

\section{References}

1. Morrish NJ, Wang SL, Stevens LK, Fuller JH, Keen H: Mortality and causes of death in the WHO Multinational Study of Vascular Disease in Diabetes. Diabetologia 2001, 44 Suppl 2:S14-21.

2. Birkeland KI, Jørgensen ME, Carstensen B, Persson F, Gulseth HL, Thuresson M, Fenici P, Nathanson D, Nyström T, Eriksson JW et al: Cardiovascular mortality and morbidity in patients with type 2 diabetes following initiation of sodium-glucose co-transporter-2 inhibitors versus other glucoselowering drugs (CVD-REAL Nordic): a multinational observational analysis. The lancet Diabetes \& endocrinology 2017, 5(9):709-717.

3. Kosiborod M, Lam CSP, Kohsaka S, Kim DJ, Karasik A, Shaw J, Tangri N, Goh SY, Thuresson M, Chen $\mathrm{H}$ et al: Cardiovascular Events Associated With SGLT-2 Inhibitors Versus Other Glucose-Lowering Drugs: The CVD-REAL 2 Study. Journal of the American College of Cardiology 2018, 71(23):26282639.

4. Seufert J: SGLT2 inhibitors - an insulin-independent therapeutic approach for treatment of type 2 diabetes: focus on canagliflozin. Diabetes, metabolic syndrome and obesity : targets and therapy 2015, 8:543-554.

5. Lahnwong S, Chattipakorn SC, Chattipakorn N: Potential mechanisms responsible for cardioprotective effects of sodium-glucose co-transporter 2 inhibitors. Cardiovascular diabetology 2018, 17(1):101.

6. Fei Y, Tsoi MF, Cheung BMY: Cardiovascular outcomes in trials of new antidiabetic drug classes: a network meta-analysis. Cardiovascular diabetology 2019, 18(1):112.

7. McGuire DK, Shih WJ, Cosentino F, Charbonnel B, Cherney DZI, Dagogo-Jack S, Pratley R, Greenberg M, Wang S, Huyck S et al: Association of SGLT2 Inhibitors With Cardiovascular and Kidney Outcomes in Patients With Type 2 Diabetes: A Meta-analysis. JAMA cardiology 2020. 
8. Wanner C, Lachin JM, Inzucchi SE, Fitchett D, Mattheus M, George J, Woerle HJ, Broedl UC, von Eynatten M, Zinman B: Empagliflozin and Clinical Outcomes in Patients With Type 2 Diabetes Mellitus, Established Cardiovascular Disease, and Chronic Kidney Disease. Circulation 2018, 137(2):119-129.

9. Perkovic V, de Zeeuw D, Mahaffey KW, Fulcher G, Erondu N, Shaw W, Barrett TD, Weidner-Wells M, Deng $\mathrm{H}$, Matthews DR et al: Canagliflozin and renal outcomes in type 2 diabetes: results from the CANVAS Program randomised clinical trials. The lancet Diabetes \& endocrinology 2018, 6(9):691704.

10. Singh JS, Fathi A, Vickneson K, Mordi I, Mohan M, Houston JG, Pearson ER, Struthers AD, Lang CC: Research into the effect Of SGLT2 inhibition on left ventricular remodelling in patients with heart failure and diabetes mellitus (REFORM) trial rationale and design. Cardiovascular diabetology 2016, 15:97.

11. Cumpston M, Li T, Page MJ, Chandler J, Welch VA, Higgins JP, Thomas J: Updated guidance for trusted systematic reviews: a new edition of the Cochrane Handbook for Systematic Reviews of Interventions. The Cochrane database of systematic reviews 2019, 10:Ed000142.

12. Zinman B, Wanner C, Lachin JM, Fitchett D, Bluhmki E, Hantel S, Mattheus M, Devins T, Johansen OE, Woerle HJ et al: Empagliflozin, Cardiovascular Outcomes, and Mortality in Type 2 Diabetes. The New England journal of medicine 2015, 373(22):2117-2128.

13. Neal B, Perkovic V, Mahaffey KW, de Zeeuw D, Fulcher G, Erondu N, Shaw W, Law G, Desai M, Matthews DR: Canagliflozin and Cardiovascular and Renal Events in Type 2 Diabetes. The New England journal of medicine 2017, 377(7):644-657.

14. Kosiborod M, Gause-Nilsson I, Xu J, Sonesson C, Johnsson E: Efficacy and safety of dapagliflozin in patients with type 2 diabetes and concomitant heart failure. Journal of diabetes and its complications 2017, 31(7):1215-1221.

15. Perkovic V, Jardine MJ, Neal B, Bompoint S, Heerspink HJL, Charytan DM, Edwards R, Agarwal R, Bakris G, Bull S et al: Canagliflozin and Renal Outcomes in Type 2 Diabetes and Nephropathy. The New England journal of medicine 2019, 380(24):2295-2306.

16. Furtado RHM, Bonaca MP, Raz I, Zelniker TA, Mosenzon O, Cahn A, Kuder J, Murphy SA, Bhatt DL, Leiter LA et al: Dapagliflozin and Cardiovascular Outcomes in Patients With Type 2 Diabetes Mellitus and Previous Myocardial Infarction. Circulation 2019, 139(22):2516-2527.

17. McMurray JJV, Solomon SD, Inzucchi SE, Køber L, Kosiborod MN, Martinez FA, Ponikowski P, Sabatine MS, Anand IS, Bělohlávek J et al: Dapagliflozin in Patients with Heart Failure and Reduced Ejection Fraction. The New England journal of medicine 2019, 381(21):1995-2008.

18. Nassif ME, Windsor SL, Tang F, Khariton Y, Husain M, Inzucchi SE, McGuire DK, Pitt B, Scirica BM, Austin B et al: Dapagliflozin Effects on Biomarkers, Symptoms, and Functional Status in Patients With Heart Failure With Reduced Ejection Fraction: The DEFINE-HF Trial. Circulation 2019, 140(18):1463-1476. 
19. Bhatt DL, Szarek M, Steg PG, Cannon CP, Leiter LA, McGuire DK, Lewis JB, Riddle MC, Voors AA, Metra $\mathrm{M}$ et al: Sotagliflozin in Patients with Diabetes and Recent Worsening Heart Failure. The New England journal of medicine 2020.

20. Cannon CP, Pratley R, Dagogo-Jack S, Mancuso J, Huyck S, Masiukiewicz U, Charbonnel B, Frederich $\mathrm{R}$, Gallo S, Cosentino F et al: Cardiovascular Outcomes with Ertugliflozin in Type 2 Diabetes. The New England journal of medicine 2020, 383(15):1425-1435.

21. Packer M, Anker SD, Butler J, Filippatos G, Pocock SJ, Carson P, Januzzi J, Verma S, Tsutsui H, Brueckmann $\mathrm{M}$ et al: Cardiovascular and Renal Outcomes with Empagliflozin in Heart Failure. The New England journal of medicine 2020, 383(15):1413-1424.

22. Kato ET, Silverman MG, Mosenzon O, Zelniker TA, Cahn A, Furtado RHM, Kuder J, Murphy SA, Bhatt DL, Leiter LA et al: Effect of Dapagliflozin on Heart Failure and Mortality in Type 2 Diabetes Mellitus. Circulation 2019, 139(22):2528-2536.

23. Cosentino F, Cannon CP, Cherney DZI, Masiukiewicz U, Pratley R, Dagogo-Jack S, Frederich R, Charbonnel B, Mancuso J, Shih WJ et al: Efficacy of Ertugliflozin on Heart Failure-Related Events in Patients With Type 2 Diabetes Mellitus and Established Atherosclerotic Cardiovascular Disease: Results of the VERTIS CV Trial. Circulation 2020, 142(23):2205-2215.

24. Tang H, Fang Z, Wang T, Cui W, Zhai S, Song Y: Meta-Analysis of Effects of Sodium-Glucose Cotransporter 2 Inhibitors on Cardiovascular Outcomes and All-Cause Mortality Among Patients With Type 2 Diabetes Mellitus. The American journal of cardiology 2016, 118(11):1774-1780.

25. Monami M, Dicembrini I, Mannucci E: Effects of SGLT-2 inhibitors on mortality and cardiovascular events: a comprehensive meta-analysis of randomized controlled trials. Acta diabetologica 2017, 54(1):19-36.

26. Silverii GA, Monami M, Mannucci E: Sodium-glucose co-transporter-2 inhibitors and all-cause mortality: A meta-analysis of randomized controlled trials. Diabetes, obesity \& metabolism 2020.

27. Zhang XL, Zhu QQ, Chen YH, Li XL, Chen F, Huang JA, Xu B: Cardiovascular Safety, Long-Term Noncardiovascular Safety, and Efficacy of Sodium-Glucose Cotransporter 2 Inhibitors in Patients With Type 2 Diabetes Mellitus: A Systemic Review and Meta-Analysis With Trial Sequential Analysis. Journal of the American Heart Association 2018, 7(2).

28. Castellana M, Procino F, Sardone R, Trimboli P, Giannelli G: Generalizability of sodium-glucose cotransporter-2 inhibitors cardiovascular outcome trials to the type 2 diabetes population: a systematic review and meta-analysis. Cardiovascular diabetology 2020, 19(1):87.

29. Zelniker TA, Wiviott SD, Raz I, Im K, Goodrich EL, Bonaca MP, Mosenzon O, Kato ET, Cahn A, Furtado RHM et al: SGLT2 inhibitors for primary and secondary prevention of cardiovascular and renal outcomes in type 2 diabetes: a systematic review and meta-analysis of cardiovascular outcome trials. Lancet (London, England) 2019, 393(10166):31-39.

30. Zinman B, Inzucchi SE, Lachin JM, Wanner C, Ferrari R, Fitchett D, Bluhmki E, Hantel S, KempthorneRawson J, Newman J et al: Rationale, design, and baseline characteristics of a randomized, placebo- 
controlled cardiovascular outcome trial of empagliflozin (EMPA-REG OUTCOME ${ }^{\mathrm{TM}}$ ). Cardiovascular diabetology 2014, 13:102.

31. Neal B, Perkovic V, Matthews DR, Mahaffey KW, Fulcher G, Meininger G, Erondu N, Desai M, Shaw W, Vercruysse $\mathrm{F}$ et al: Rationale, design and baseline characteristics of the CANagliflozin cardioVascular Assessment Study-Renal (CANVAS-R): A randomized, placebo-controlled trial. Diabetes, obesity \& metabolism 2017, 19(3):387-393.

32. Mahaffey KW, Neal B, Perkovic V, de Zeeuw D, Fulcher G, Erondu N, Shaw W, Fabbrini E, Sun T, Li Q et al: Canagliflozin for Primary and Secondary Prevention of Cardiovascular Events: Results From the CANVAS Program (Canagliflozin Cardiovascular Assessment Study). Circulation 2018, 137(4):323334.

33. Rådholm K, Figtree G, Perkovic V, Solomon SD, Mahaffey KW, de Zeeuw D, Fulcher G, Barrett TD, Shaw W, Desai $\mathrm{M}$ et al: Canagliflozin and Heart Failure in Type 2 Diabetes Mellitus: Results From the CANVAS Program. Circulation 2018, 138(5):458-468.

34. Mahaffey KW, Jardine MJ, Bompoint S, Cannon CP, Neal B, Heerspink HJL, Charytan DM, Edwards R, Agarwal R, Bakris $\mathrm{G}$ et al: Canagliflozin and Cardiovascular and Renal Outcomes in Type 2 Diabetes Mellitus and Chronic Kidney Disease in Primary and Secondary Cardiovascular Prevention Groups. Circulation 2019, 140(9):739-750.

35. Jardine MJ, Zhou Z, Mahaffey KW, Oshima M, Agarwal R, Bakris G, Bajaj HS, Bull S, Cannon CP, Charytan DM et al: Renal, Cardiovascular, and Safety Outcomes of Canagliflozin by Baseline Kidney Function: A Secondary Analysis of the CREDENCE Randomized Trial. Journal of the American Society of Nephrology : JASN 2020, 31(5):1128-1139.

36. Wiviott SD, Raz I, Bonaca MP, Mosenzon O, Kato ET, Cahn A, Silverman MG, Bansilal S, Bhatt DL, Leiter LA et al: The design and rationale for the Dapagliflozin Effect on Cardiovascular Events (DECLARE)-TIMI 58 Trial. American heart journal 2018, 200:83-89.

37. Wiviott SD, Raz I, Bonaca MP, Mosenzon O, Kato ET, Cahn A, Silverman MG, Zelniker TA, Kuder JF, Murphy SA et al: Dapagliflozin and Cardiovascular Outcomes in Type 2 Diabetes. The New England journal of medicine 2019, 380(4):347-357.

38. Cannon CP, McGuire DK, Pratley R, Dagogo-Jack S, Mancuso J, Huyck S, Charbonnel B, Shih WJ, Gallo S, Masiukiewicz $\mathrm{U}$ et al: Design and baseline characteristics of the eValuation of ERTugliflozin efflcacy and Safety CardioVascular outcomes trial (VERTIS-CV). American heart journal 2018, 206:11-23.

39. Kosiborod M, Birkeland KI, Cavender MA, Fu AZ, Wilding JP, Khunti K, Holl RW, Norhammar A, Jørgensen ME, Wittbrodt ET et al: Rates of myocardial infarction and stroke in patients initiating treatment with SGLT2-inhibitors versus other glucose-lowering agents in real-world clinical practice: Results from the CVD-REAL study. Diabetes, obesity \& metabolism 2018, 20(8):1983-1987.

40. Sinha B, Ghosal S: Meta-analyses of the effects of DPP-4 inhibitors, SGLT2 inhibitors and GLP1 receptor analogues on cardiovascular death, myocardial infarction, stroke and hospitalization for heart failure. Diabetes research and clinical practice 2019, 150:8-16. 
41. Lim VG, Bell RM, Arjun S, Kolatsi-Joannou M, Long DA, Yellon DM: SGLT2 Inhibitor, Canagliflozin, Attenuates Myocardial Infarction in the Diabetic and Nondiabetic Heart. JACC Basic to translational science $2019,4(1): 15-26$.

42. Farahani P: Non-severe Hypoglycemia Risk Difference between Sulfonylurea and Sodium-Glucose Cotransporter-2 Inhibitors (SGLT2-I) as an Add-On to Metformin in Randomized Controlled Trials. Journal of population therapeutics and clinical pharmacology = Journal de la therapeutique des populations et de la pharmacologie clinique 2017, 24(2):e32-e40.

43. Horii T, Oikawa Y, Kunisada N, Shimada A, Atsuda K: Real-world risk of hypoglycemia-related hospitalization in Japanese patients with type 2 diabetes using SGLT2 inhibitors: a nationwide cohort study. BMJ open diabetes research \& care 2020, 8(2).

44. Fralick M, Schneeweiss S, Patorno E: Risk of Diabetic Ketoacidosis after Initiation of an SGLT2 Inhibitor. The New England journal of medicine 2017, 376(23):2300-2302.

45. Tsimihodimos V, Filippatos TD, Elisaf MS: SGLT2 inhibitors and the kidney: Effects and mechanisms. Diabetes \& metabolic syndrome 2018, 12(6):1117-1123.

46. Kelly MS, Lewis J, Huntsberry AM, Dea L, Portillo I: Efficacy and renal outcomes of SGLT2 inhibitors in patients with type 2 diabetes and chronic kidney disease. Postgraduate medicine 2019, 131(1):3142.

47. Neuen BL, Young T, Heerspink HJL, Neal B, Perkovic V, Billot L, Mahaffey KW, Charytan DM, Wheeler DC, Arnott C et al: SGLT2 inhibitors for the prevention of kidney failure in patients with type 2 diabetes: a systematic review and meta-analysis. The lancet Diabetes \& endocrinology 2019 , 7(11):845-854.

48. Sung J, Padmanabhan S, Gurung S, Inglis S, Vicaretti M, Begg L, Cheung NW, Girgis CM: SGLT2 inhibitors and amputation risk: Real-world data from a diabetes foot wound clinic. Journal of clinical \& translational endocrinology 2018, 13:46-47.

49. Scheen AJ: Does lower limb amputation concern all SGLT2 inhibitors? Nature reviews Endocrinology 2018, 14(6):326-328.

50. Werkman NCC, Nielen JTH, van den Bergh JPW, Ejskjaer N, Røikjer J, Schaper NC, Rossi B, Klungel O, Vestergaard P, de Vries F et al: Use of Sodium-Glucose Co-Transporter-2-Inhibitors (SGLT2-Is) and Risk of Lower Limb Amputation. Current drug safety 2020.

51. Weber MA, Mansfield TA, Cain VA, Iqbal N, Parikh S, Ptaszynska A: Blood pressure and glycaemic effects of dapagliflozin versus placebo in patients with type 2 diabetes on combination antihypertensive therapy: a randomised, double-blind, placebo-controlled, phase 3 study. The lancet Diabetes \& endocrinology 2016, 4(3):211-220.

52. Araki E, Onishi Y, Asano M, Kim H, Yajima T: Efficacy and safety of dapagliflozin over 1 year as addon to insulin therapy in Japanese patients with type 2 diabetes: the DAISY (Dapagliflozin Added to patients under InSulin therapY) trial. Diabetes, obesity \& metabolism 2017, 19(4):562-570.

53. Menne J, Dumann E, Haller H, Schmidt BMW: Acute kidney injury and adverse renal events in patients receiving SGLT2-inhibitors: A systematic review and meta-analysis. PLoS medicine 2019, 
16(12):e1002983.

54. Giugliano D, Esposito K: Class effect for SGLT-2 inhibitors: a tale of 9 drugs. Cardiovascular diabetology 2019, 18(1):94.

55. Scheen AJ: An update on the safety of SGLT2 inhibitors. Expert opinion on drug safety 2019, 18(4):295-311.

56. Giugliano D, De Nicola L, Maiorino MI, Bellastella G, Esposito K: Type 2 diabetes and the kidney: Insights from cardiovascular outcome trials. Diabetes, obesity \& metabolism 2019, 21(8):1790-1800.

\section{Figures}




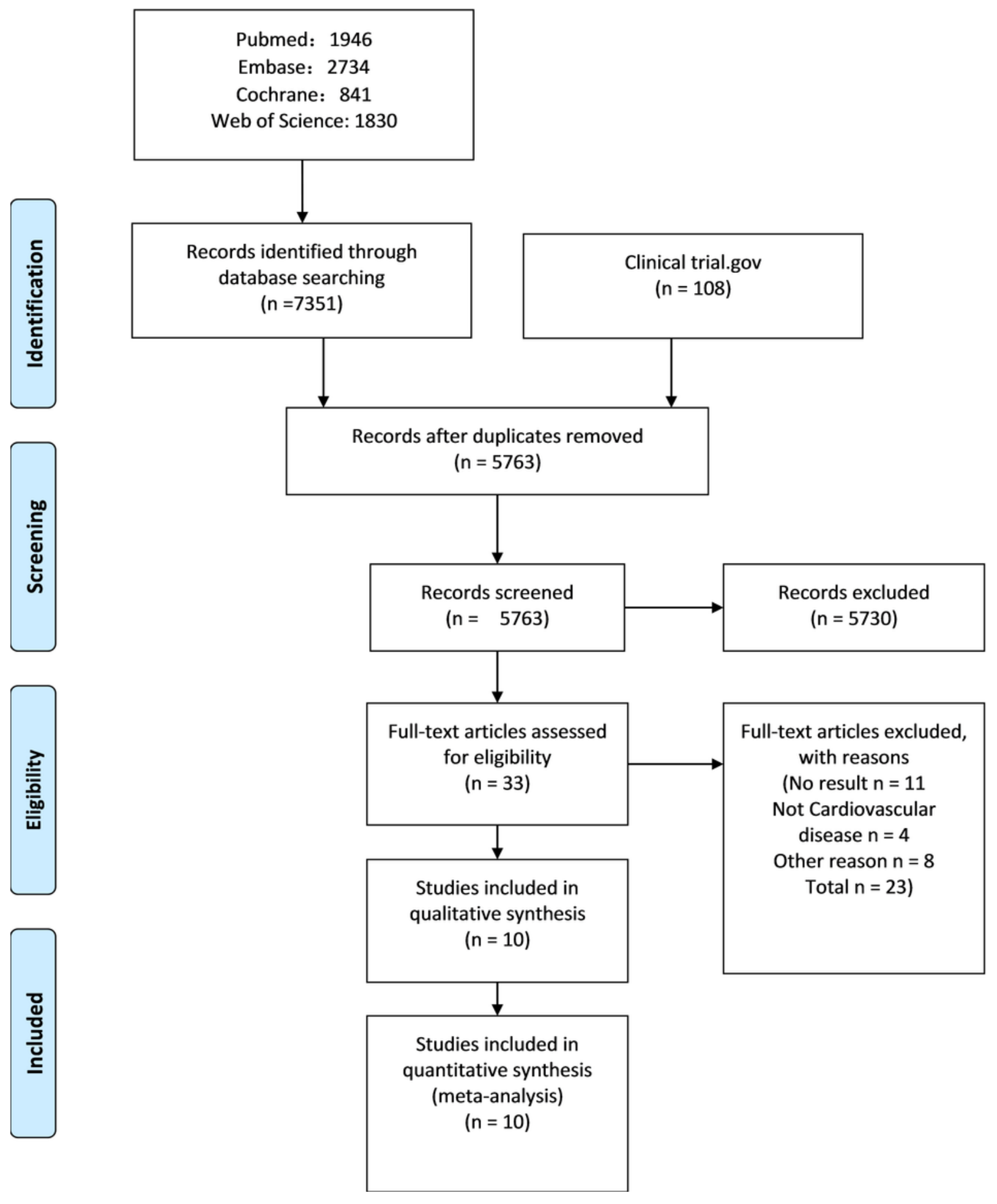

Figure 1

Literature screening and selection flow chart. 
experimental control Risk Ratio

Risk Ratio

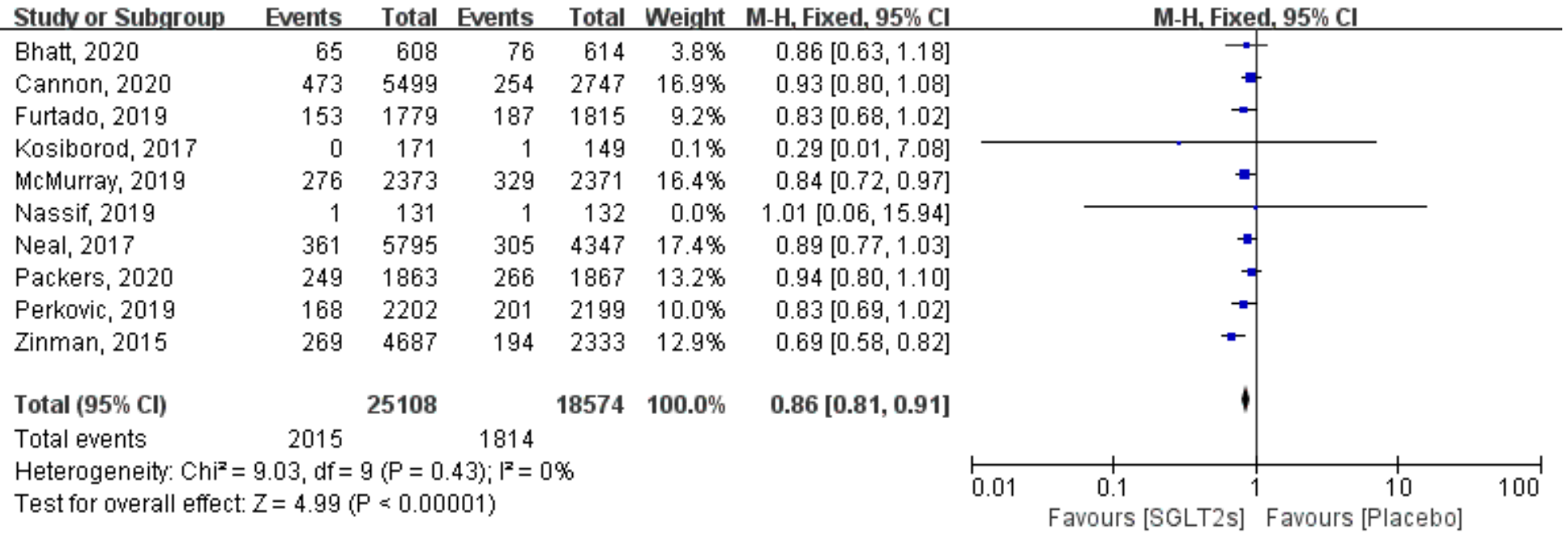

Figure 2

Forest plot of meta-analysis for the comparison of all-cause mortality between the SGLT-2 and placebo groups.

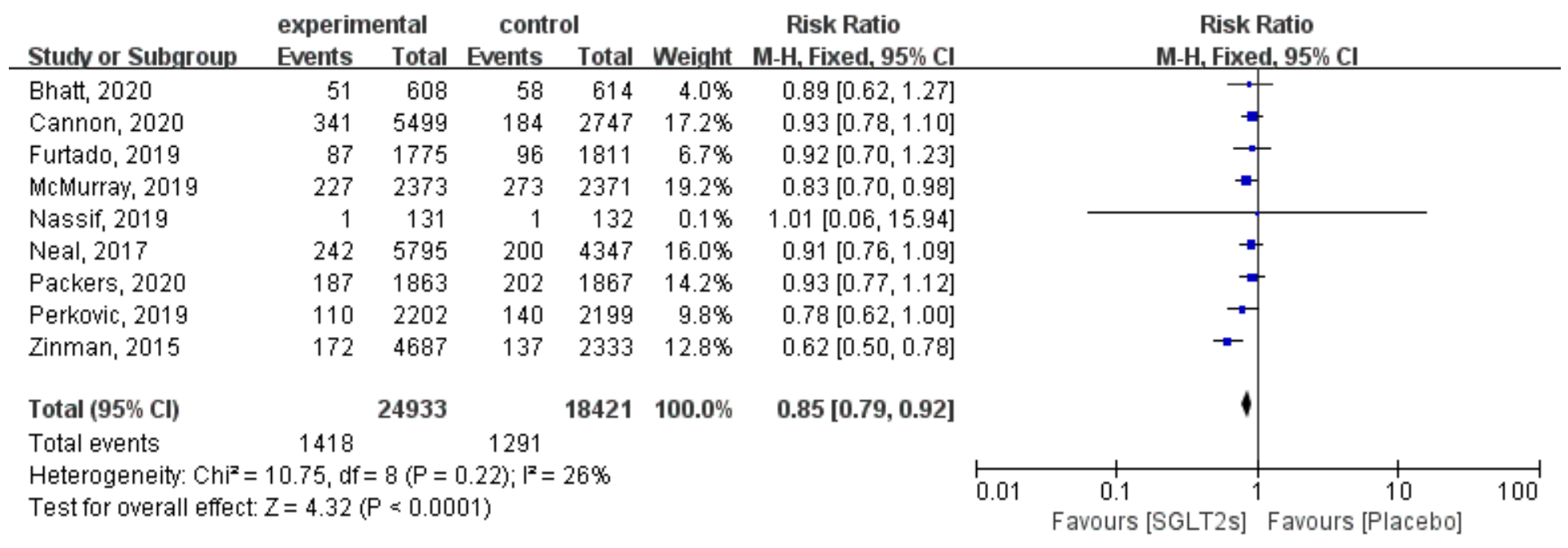

\section{Figure 3}

Forest plot of meta-analysis for the comparison of cardiovascular death between the SGLT-2 and placebo groups. 
Experimental Control

Studv or Subgroup

\section{Bhatt, 2020}

Cannon, 2020

Furtado, 2019

Kosiborod, 2017

McMurray, 2019

Neal, 2017

Packers, 2020

Perkovic, 2019

Zinman, 2015

Total $(95 \% \mathrm{Cl})$

Total events

Heterogeneity: $\mathrm{Chi}^{2}=4.87, \mathrm{df}=8(\mathrm{P}=0.77) ; \mathrm{I}^{2}=0 \%$

Test for overall effect: $Z=10.53$ ( $P<0.00001$ )

Events

Total Events

$231 \quad 2373$

$115 \quad 5795$

$126 \quad 4687$

24959
Risk Ratio

Risk Ratio

Total Weight M-H, Fixed, 95\% Cl

$\begin{array}{llllll}194 & 608 & 297 & 614 & 18.1 \% & 0.66[0.57,0.76]\end{array}$

$\begin{array}{lllll}139 & 5499 & 99 & 2747 & 8.1 \%\end{array}$

$\begin{array}{lllll}81 & 1761 & 114 & 1809 & 6.9 \%\end{array}$

$\begin{array}{lllll}1 & 171 & 7 & 149 & 0.5 \%\end{array}$

$\begin{array}{lll}318 & 2371 \quad 19.5 \%\end{array}$

$\begin{array}{lll}136 & 4347 & 9.5 \%\end{array}$

$3421867 \quad 21.0 \%$

$\begin{array}{lll}141 & 2199 \quad 8.7 \%\end{array}$

$95 \quad 2333 \quad 7.8 \%$

$0.70[0.54,0.90]$

$0.73[0.55,0.96]$

$0.12[0.02,1.00]$

$0.73[0.62,0.85]$

$0.63[0.50,0.81]$

$0.72[0.62,0.84]$

$0.63[0.49,0.82]$

$0.66[0.51,0.86]$

$18436100.0 \%$

$0.69[0.64,0.74]$

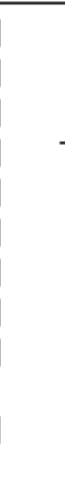
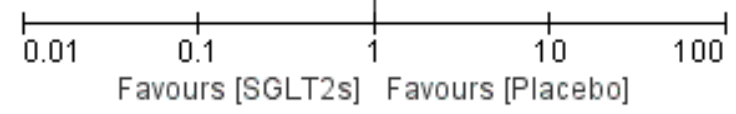

\section{Figure 4}

Forest plot of meta-analysis for the comparison of HHF between the SGLT-2 and placebo groups.

a

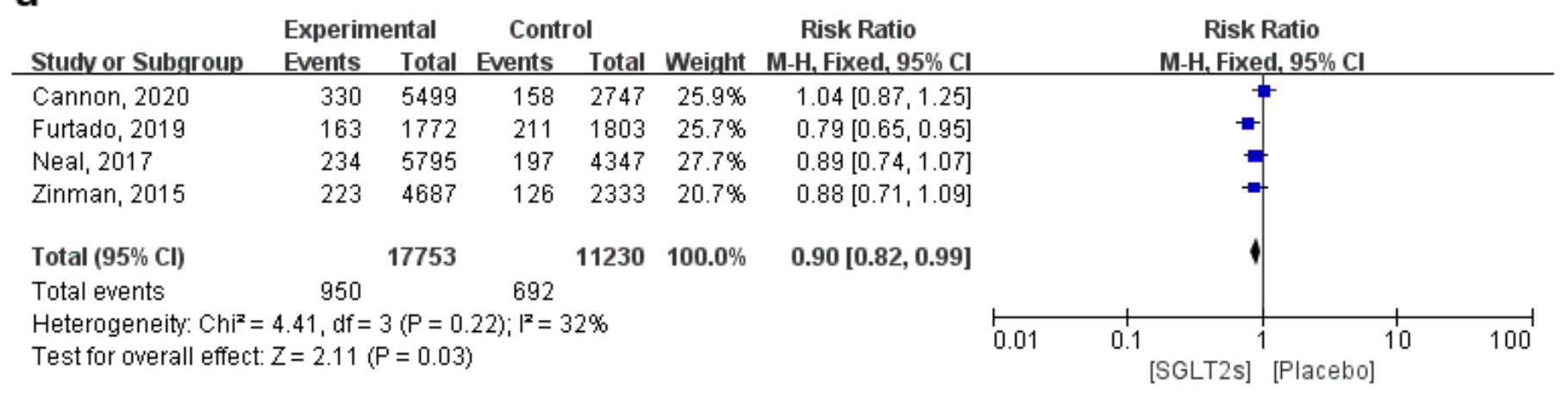

b

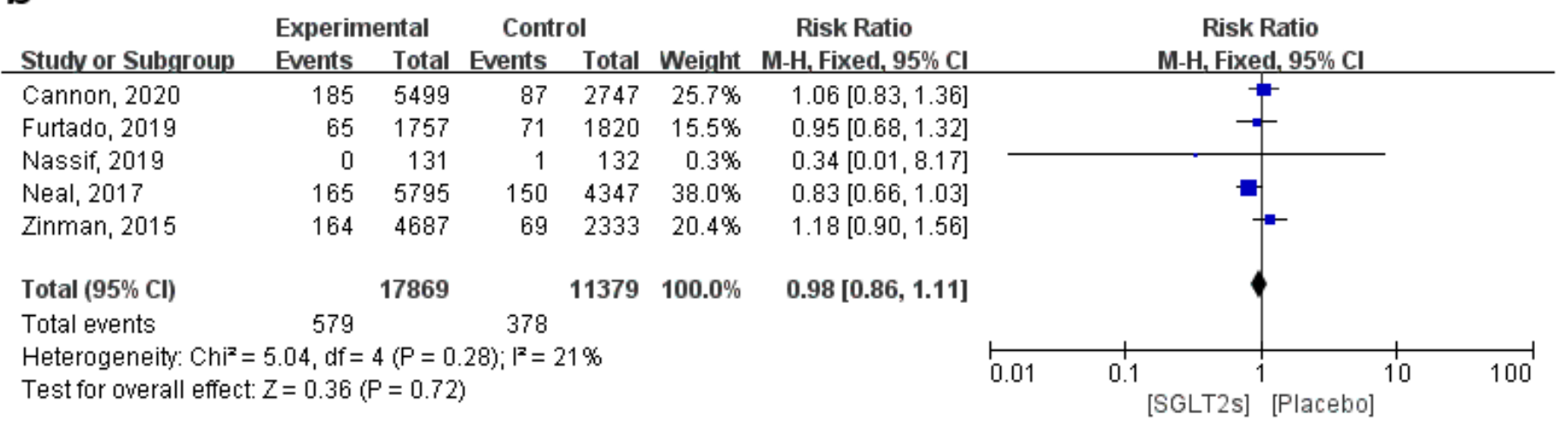

\section{Figure 5}

Forest plot of meta-analysis for the comparison of adverse cardiovascular events between SGLT-2 and placebo groups. (a) Myocardial infarction adverse outcomes, (b) stroke adverse outcomes. 


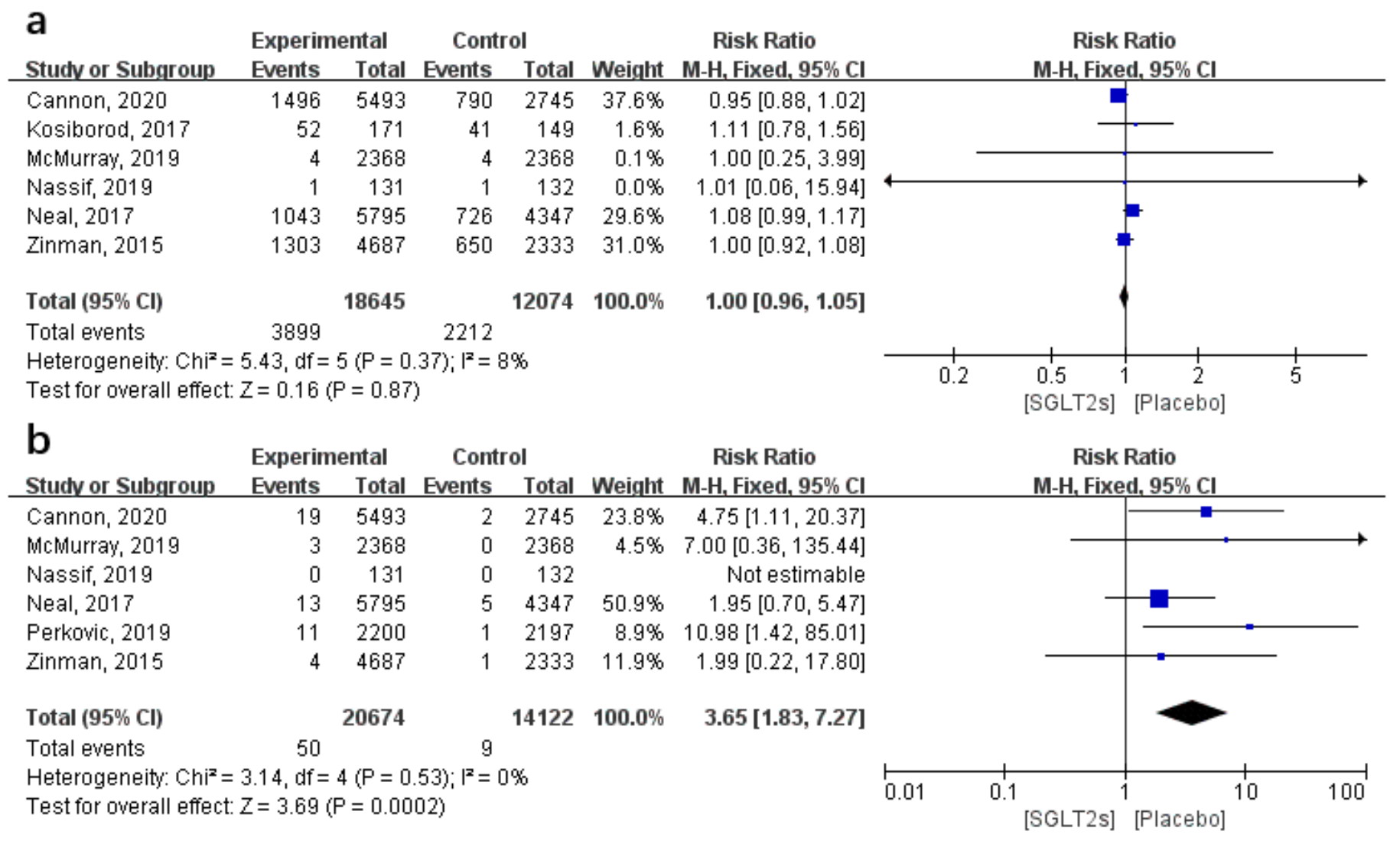

\section{Figure 6}

Forest plot of meta-analysis for the comparison of adverse endocrine events between the SGLT-2 and placebo groups. (a) Hypoglycaemia adverse outcomes, (b) diabetic ketoacidosis adverse outcomes. 


\section{a}

Experimental Control Risk Ratio

Risk Ratio

Study or Subgroup Events Total Events Total Weight M-H, Fixed, 95\% Cl

\begin{tabular}{lrrrrrr} 
Kosiborod, 2017 & 29 & 171 & 8 & 149 & $1.2 \%$ & $3.16[1.49,6.70]$ \\
McMurray, 2019 & 153 & 2368 & 170 & 2368 & $24.4 \%$ & $0.90[0.73,1.11]$ \\
Neal, 2017 & 411 & 5795 & 272 & 4347 & $44.6 \%$ & $1.13[0.98,1.31]$ \\
Zinman, 2015 & 246 & 4687 & 155 & 2333 & $29.7 \%$ & $0.79[0.65,0.96]$ \\
& & & & & & \\
Total (95\% Cl) & & $\mathbf{1 3 0 2 1}$ & & $\mathbf{9 1 9 7}$ & $\mathbf{1 0 0 . 0} \%$ & $\mathbf{1 . 0 0}[\mathbf{0 . 9 0 , 1 . 1 1 ]}$ \\
Total events & 839 & \multicolumn{5}{c}{605}
\end{tabular}

Heterogeneity: $\mathrm{Chi}^{2}=18.34, \mathrm{df}=3(\mathrm{P}=0.0004) ; \mathrm{I}^{2}=84 \%$

Test for overall effect: $Z=0.01(P=0.99)$

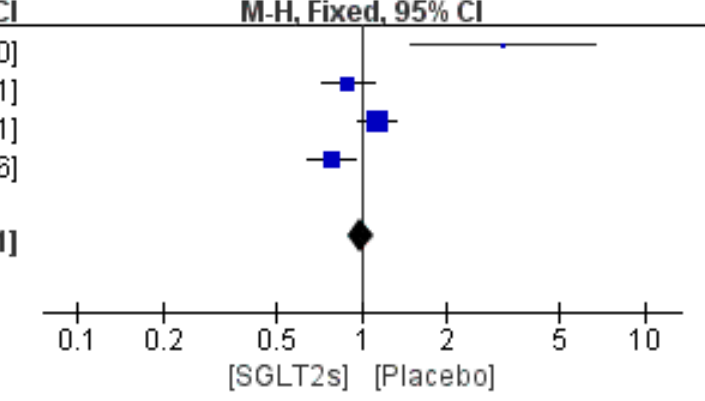

b Experimental Control
Events Total Events

Risk Ratio

Risk Ratio

Studv or Subgroup Total Weight M-H, Fixed, $95 \% \mathrm{Cl}$

Cannon, 2020

Kosiborod, 2017

McMurray, 2019

Nassif, 2019

Neal, 2017

Perkovic, 2019

Zinman, 2015

$\begin{array}{rrr}101 & 5493 & 60 \\ 7 & 171 & 2\end{array}$

$\begin{array}{llll}60 & 2745 & 23.3 \% & 0.84[0.61,1.15\end{array}$

$\begin{array}{lll}149 & 0.6 \% & 3.05 \\ {[0.64,14.46]}\end{array}$

$\begin{array}{llllll}28 & 2373 & 39 & 2371 & 11.4 \% & 0.72[0.44,1.16]\end{array}$

$\begin{array}{llllll}1 & 131 & 1 & 132 & 0.3 \% & 1.01[0.06,15.94]\end{array}$

$63 \quad 5795$

$64 \quad 4347 \quad 21.3 \%$

$0.74[0.52,1.04]$

$\begin{array}{llllll}86 & 2200 & 98 & 2197 & 28.6 \% & 0.88[0.66,1.16]\end{array}$

$45 \quad 4687$

$37 \quad 2333 \quad 14.4 \%$

$0.61[0.39,0.93]$

Total $(95 \% \mathrm{Cl})$

20850

$14274100.0 \%$

$0.80[0.68,0.93]$

Total events $331 \quad 301$

Heterogeneity: $\mathrm{Chi}^{2}=5.35, \mathrm{df}=6(\mathrm{P}=0.50) ; \mathrm{I}^{2}=0 \%$

Test for overall effect: $Z=2.88(P=0.004)$

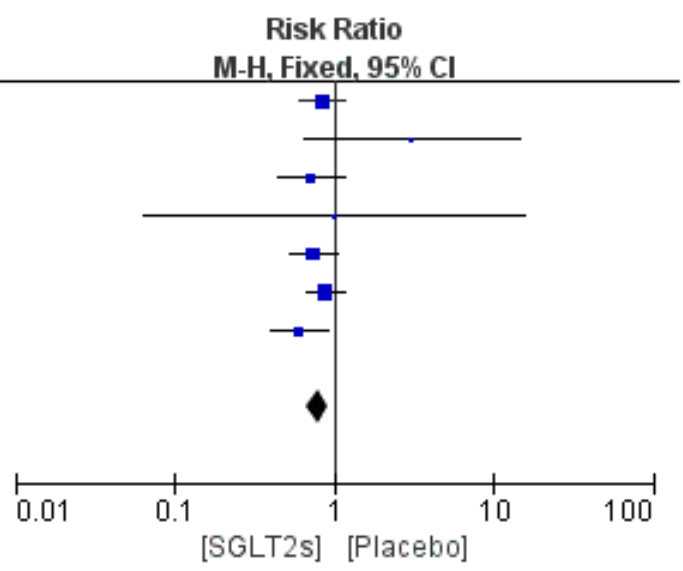

\section{Figure 7}

Forest plot of meta-analysis for the comparison of adverse renal events between the SGLT-2 and placebo groups. (a) Acute renal failure, (b) acute renal injury. 
a

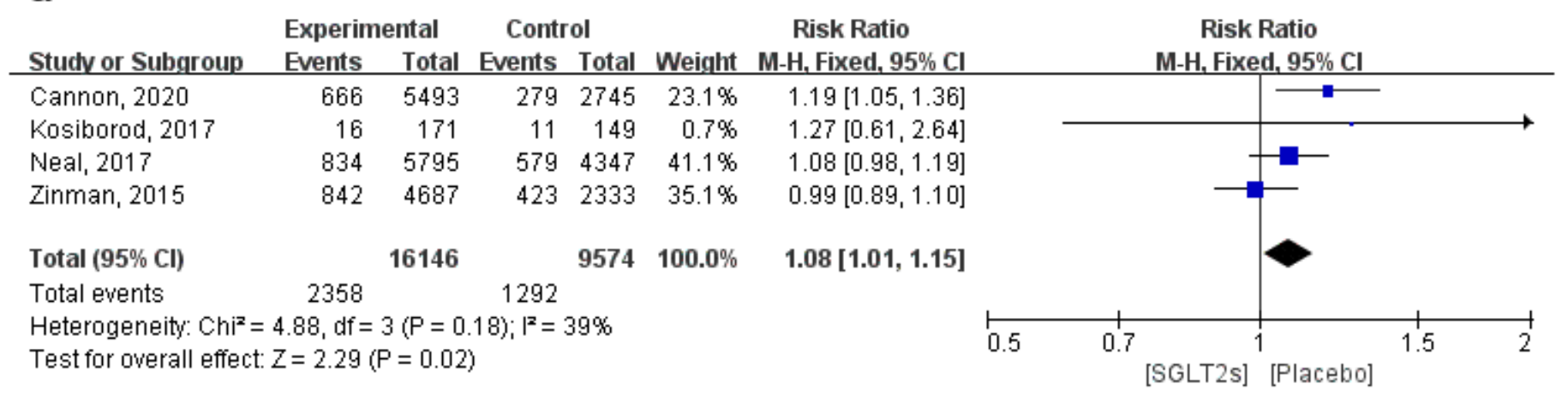

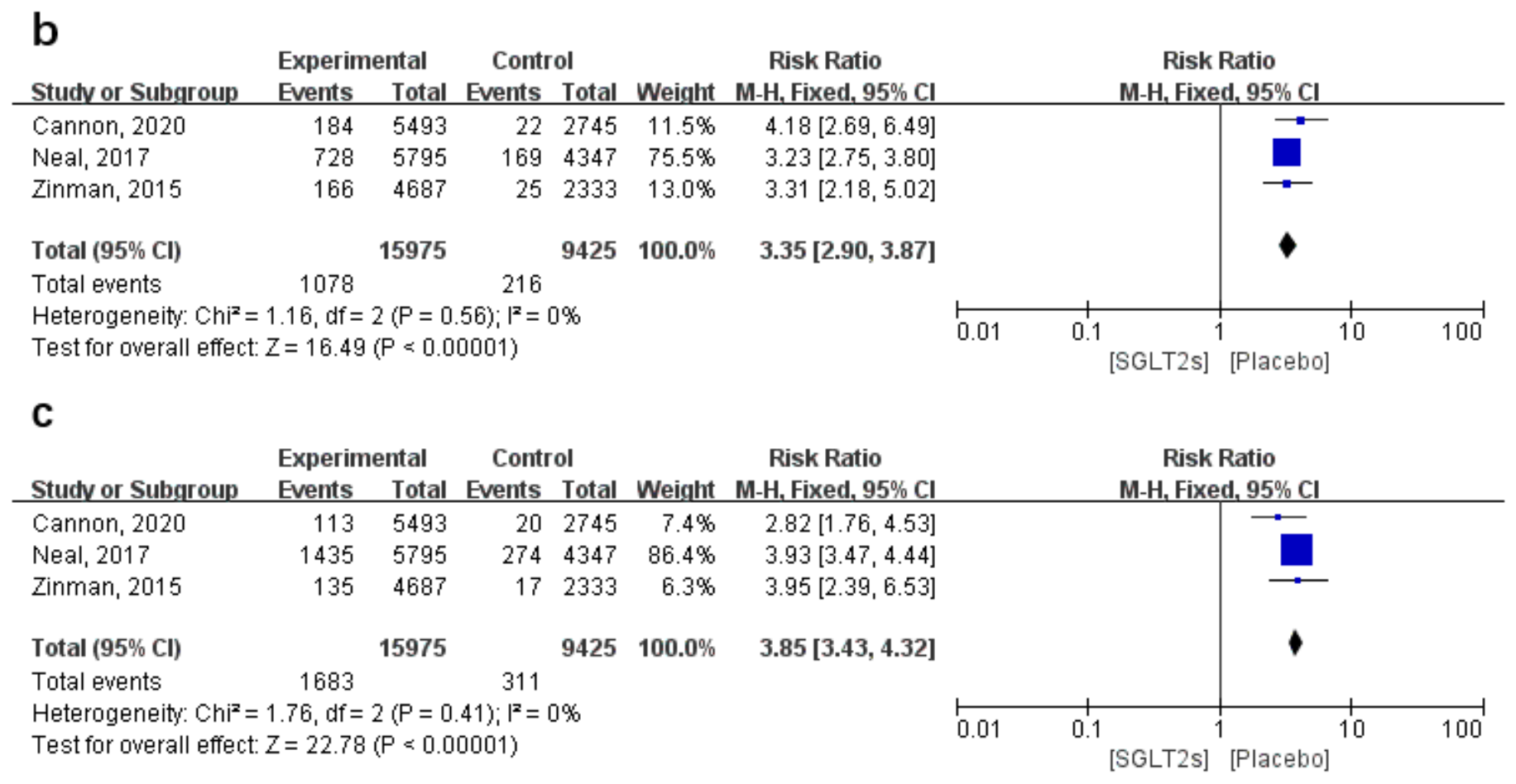

\section{Figure 8}

Forest plot of meta-analysis for the comparison of infection adverse events between the SGLT-2 and placebo groups. (a) Urinary tract infection adverse outcomes, (b) male genital infection adverse outcomes, (c) female genital infection adverse outcomes. 
a

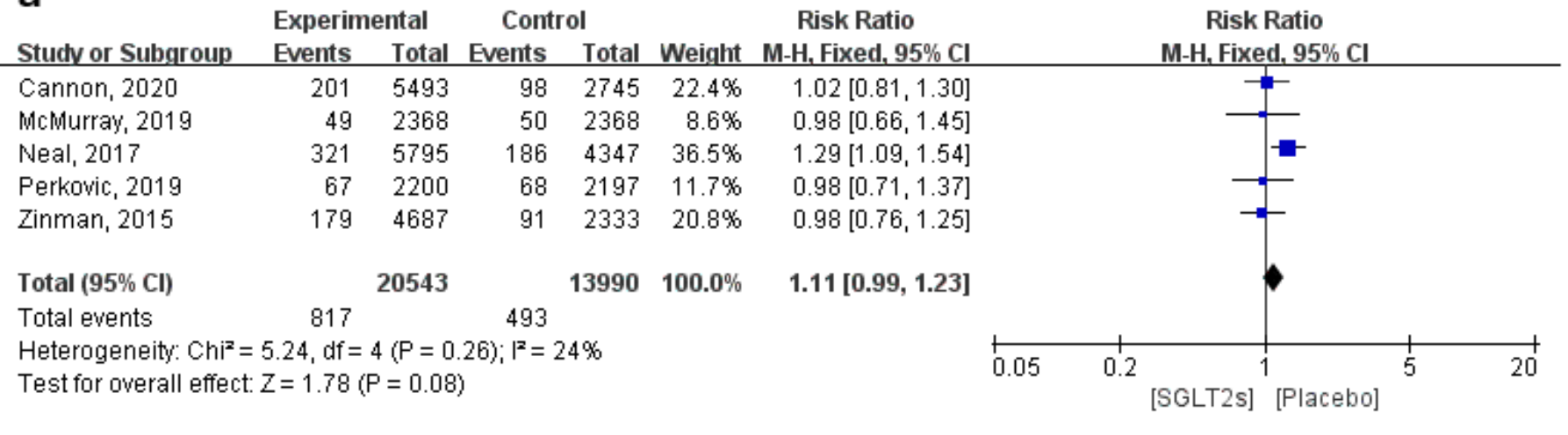

b

$\begin{array}{lll}\text { Experimental Control } & \text { Risk Ratio } \\ \text { Events Total Events Total Weight M-H. Fixed, 95 }\end{array}$

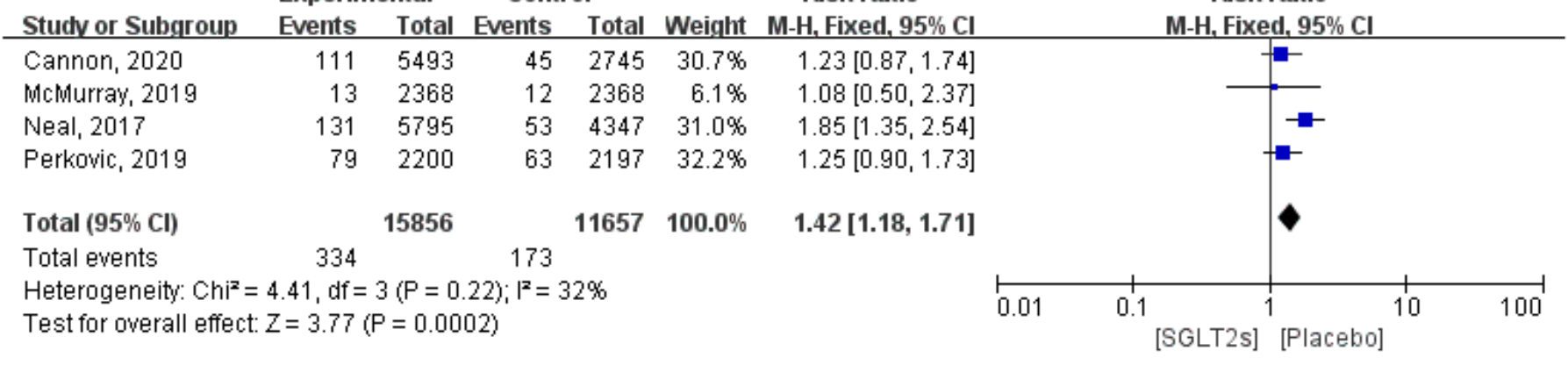

C

Experimental Control

Cannon, 2020

Kosiborod, 2017

McMurray, 2019

Nassif, 2019

Neal, 2017

Zinman, 2015

Total $(95 \% \mathrm{Cl})$

Total events

Heterogeneity: $\mathrm{Ch}^{2}=9.15, \mathrm{df}=5(\mathrm{P}=0.10) ; \mathrm{I}^{2}=45 \%$

Test for overall effect: $Z=4.22(P<0.0001)$
Risk Ratio Risk Ratio

M-H, Fixed, $95 \% \mathrm{Cl}$

$1.11[0.89,1.39]$

$0.73[0.23,2.33]$

$1.10[0.90,1.35]$

$1.73[0.70,4.25]$

$1.40[1.22,1.61]$

$1.03[0.83,1.28]$

1.22 [1.11, 1.33]

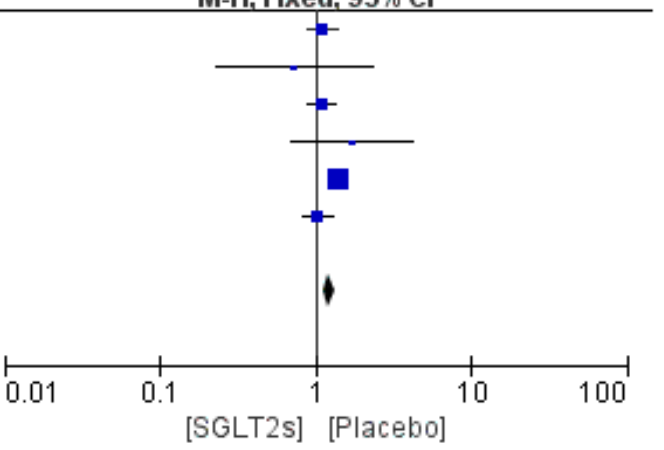

\section{Figure 9}

Forest plot of meta-analysis for the comparison of other adverse events between the SGLT-2 and placebo groups. (a) Fracture adverse outcomes, (b) amputation adverse outcomes, (c) volume depletion adverse outcomes. 
Omitting Zinman,2015

Omitting Neal,2017

Omitting Perkovic,2019

Omitting Kosiborod,2017

Omitting McMurray,2019

Omitting Nassif,2019

Omitting Cannon,2020

Omitting Furtado,2019

Omitting Packers,2020

Omitting Bhatt,2020

Fixed effect model

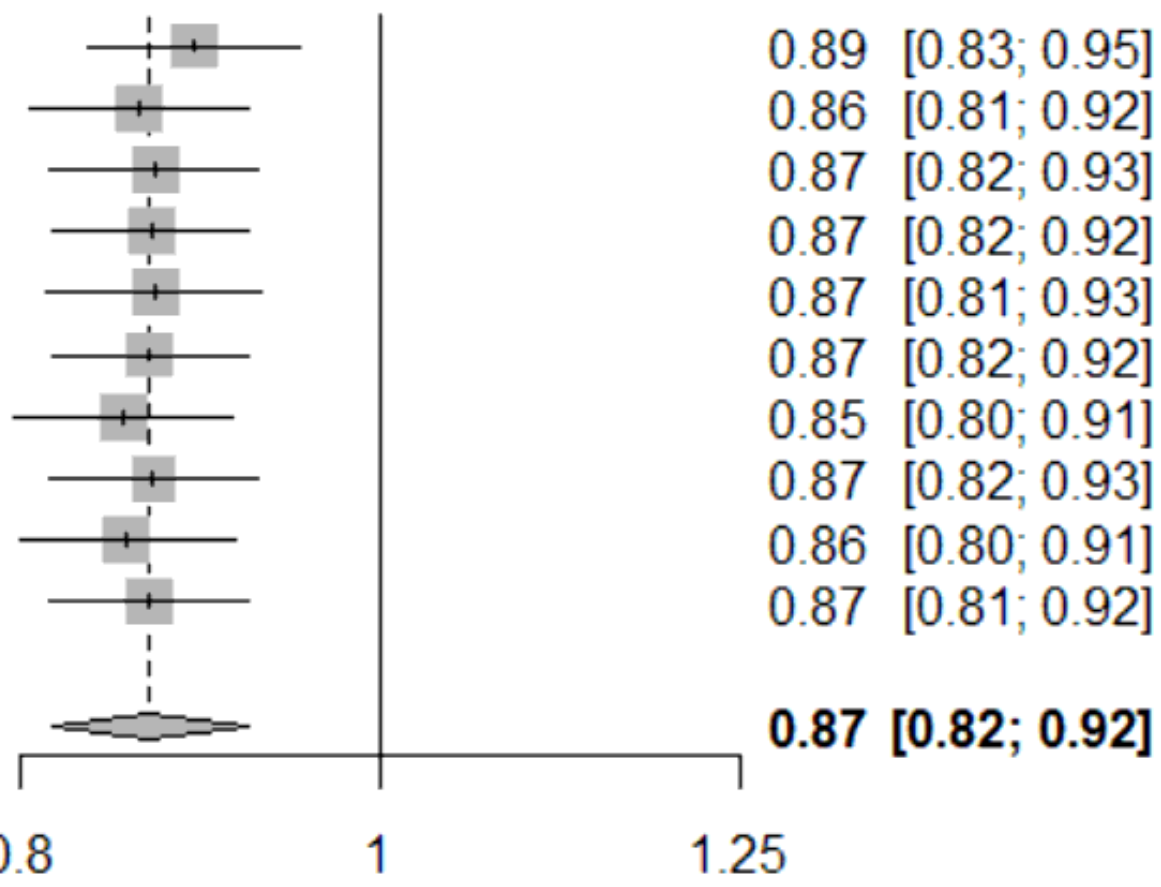

Figure 10

Forest plot of sensitivity analysis for all-cause mortality excluding individual studies.
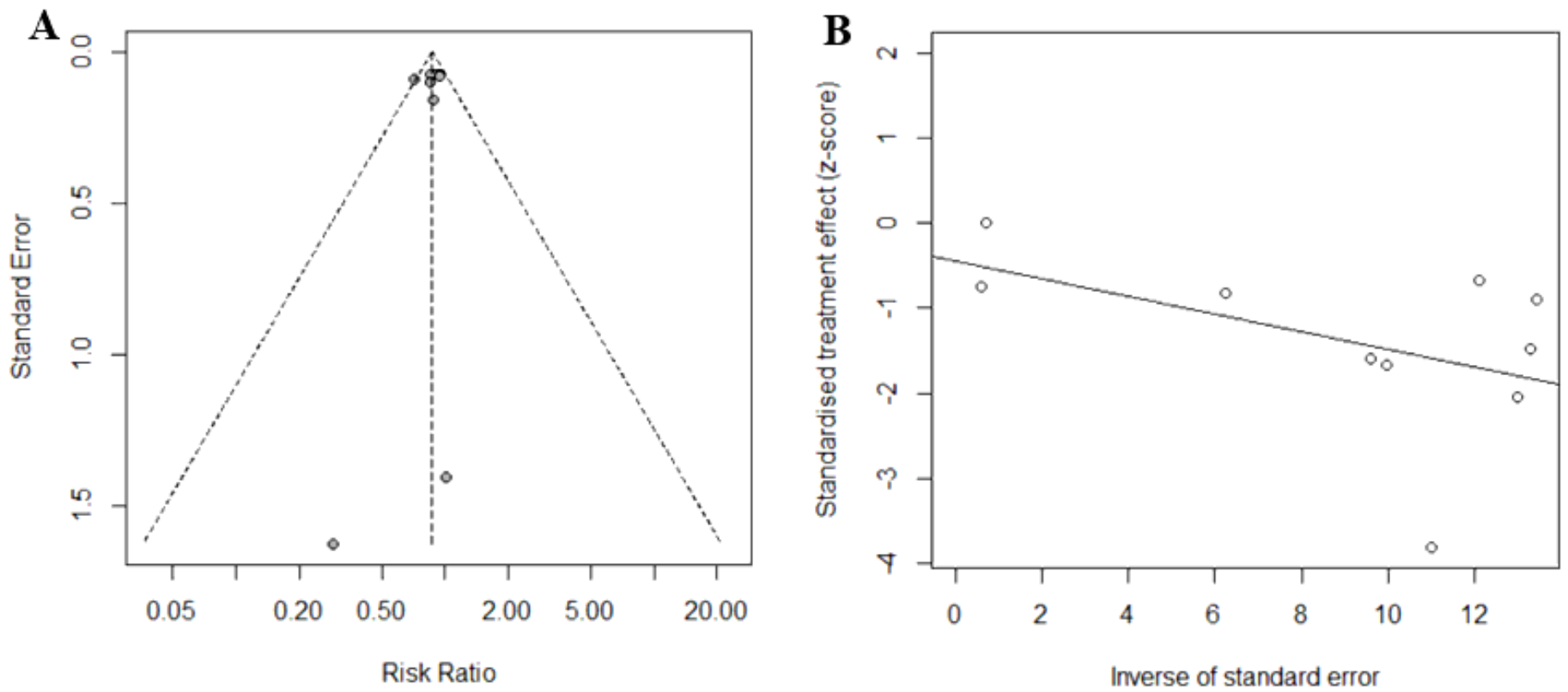

Figure 11

A: Funnel plot of all-cause mortality. B: Egger's funnel plot of all-cause mortality. 
This is a list of supplementary files associated with this preprint. Click to download.

- Appendix01.20.docx 